\title{
Halide exchanged Hoveyda-type complexes in olefin metathesis
}

\author{
Julia Wappel ${ }^{1}$, César A. Urbina-Blanco ${ }^{2}$, Mudassar Abbas ${ }^{1}$, \\ Jörg H. Albering ${ }^{1}$, Robert Saf ${ }^{1}$, Steven P. Nolan ${ }^{2}$ and Christian Slugovc ${ }^{* 1}$
}

\section{Full Research Paper}

\section{Address:}

${ }^{1}$ Institute for Chemistry and Technology of Materials (ICTM), Graz University of Technology, Stremayrgasse 9, 8010 Graz, Austria and ${ }^{2}$ EaStCHEM School of Chemistry, University of St Andrews, St Andrews KY16 9ST, United Kingdom

\section{Email:}

Julia Wappel - julia.wappel@tugraz.at;

Mudassar Abbas - mabbas@student.tugraz.at;

Steven P. Nolan - snolan@st-andrews.ac.uk;

Christian Slugovc ${ }^{*}$ - slugovc@tugraz.at

* Corresponding author

Keywords:

cross metathesis; olefin metathesis; RCM; ROMP; ruthenium

\author{
Beilstein J. Org. Chem. 2010, 6, 1091-1098. \\ doi:10.3762/bjoc. 6.125 \\ Received: 18 August 2010 \\ Accepted: 08 October 2010 \\ Published: 23 November 2010 \\ Guest Editor: K. Grela \\ (c) 2010 Wappel et al; licensee Beilstein-Institut. \\ License and terms: see end of document.
}

\begin{abstract}
The aims of this contribution are to present a straightforward synthesis of $2^{\text {nd }}$ generation Hoveyda-type olefin metathesis catalysts bearing bromo and iodo ligands, and to disclose the subtle influence of the different anionic co-ligands on the catalytic performance of the complexes in ring opening metathesis polymerisation, ring closing metathesis, enyne cycloisomerisation and cross metathesis reactions.
\end{abstract}

\section{Introduction}

Since the pioneering reports on the utilisation of $N$-heterocyclic carbenes (NHC) as co-ligands in ruthenium-based carbene complexes for olefin metathesis [1-3] in the late nineties of the last century, olefin metathesis has become a powerful carboncarbon double-bond-forming tool presenting unique synthetic opportunities [4]. Developments in this area can be attributed to a steady and competitive research, focused on improving activity, selectivity and functional group tolerance of the catalysts by changing the leaving co-ligand [4,5], by using tailored carbene ligands [5-7], by introducing new NHC ligands [5,8,9], or by variation of the anionic co-ligands [5] (Figure 1).

Compared with other modifications, little attention has been paid to the exchange of anionic co-ligands. In most cases chloro 

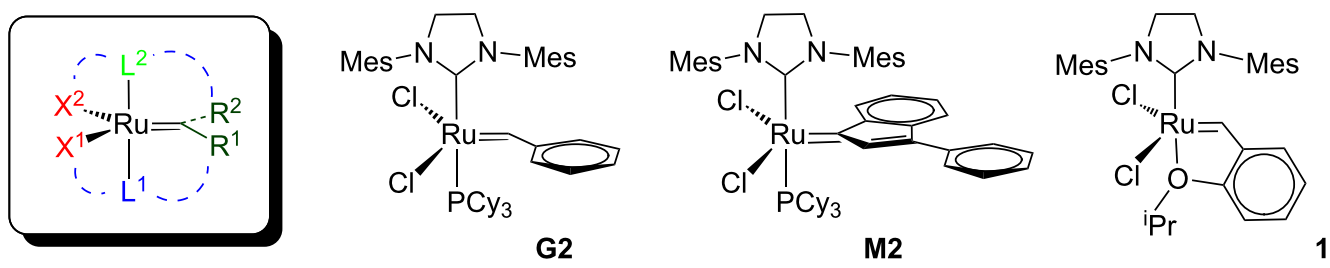

Figure 1: General layout for modifications of ruthenium-based olefin metathesis catalysts (red: anionic ligands; green: nondissociating ligand, e.g. NHC; blue: leaving group, e.g. phosphine or pyridine; olive: carbine substituents; and dashed lines symbolise possibilities of chelation). Three commercial and frequently used catalysts (G2: Grubbs $2^{\text {nd }}$ generation catalyst; M2: Neolyst M2; and 1: Hoveyda $2^{\text {nd }}$ generation catalyst).

ligands have been exchanged for sulfonates or fluorocarboxylates [10], often with the aim to heterogenise the catalysts [11], but also phenolates [12,13] and pseudohalides [14] as well as halides other than chloride [15-19]. An early study dealing with the change of reactivity upon exchanging the chloride ligands in G2 for bromides and iodides showed increasing initiation rates (phosphine dissociation is facilitated), but decreasing propagation rates with increasing steric bulk of the halides [15]. Iodide bearing catalysts have been successfully used in asymmetric olefin metathesis reactions, where they show, in most cases, better enantio- or diastereo-selectivity compared to their chloride counterparts, but at the price of lower activity [16-19]. As shown by Braddock et al., halides and more generally various anionic ligands are labile in solution, and these complexes undergo anionic ligand exchange even in nonprotic media at room temperature [20]. This particular result is an important consideration whenever charged substrates are transformed.

The lack of reactivity data for halide-exchanged complexes prompted us to investigate the catalytic activity of bromo and iodo analogues of Hoveyda $2^{\text {nd }}$ generation catalyst (1) in ring closing metathesis (RCM), enyne metathesis and cross metathesis (CM). Moreover, the scope of these compounds in ring opening metathesis polymerisation (ROMP) [21] was also studied.

\section{Results and Discussion Synthesis and characterisation}

Although complex $\mathbf{1}$ is commercially available, we prepared $\mathbf{1}$ from $\left(\mathrm{H}_{2} \mathrm{IMes}\right)\left(\mathrm{PCy}_{3}\right) \mathrm{Cl}_{2} \mathrm{Ru}$ (3-phenyl-indenylid-1-ene) (M2) as the ruthenium-containing starting material (Scheme 1). M2 is a relatively more economic alternative to $\mathbf{G 2}$, bearing an indenylidene instead of a benzylidene ligand [22-24]. Adopting Hoveyda's protocol for obtaining 1 from G2 [25] and using 1-isopropoxy-2-(prop-1-en-1-yl)benzene as the carbene precursor, 1 can be obtained in 78\% yield. Complexes $\mathbf{2}$ and $\mathbf{3}$ were prepared by addition of excess potassium bromide (KBr) or potassium iodide (KI) to a suspension of $\mathbf{1}$ in methanol, following the procedures for similar transformations of different dichloro carbene complexes to their diiodo analogues [26]. In these cases THF $[15,26]$ or acetone [27] rather than methanol were used as the solvents.

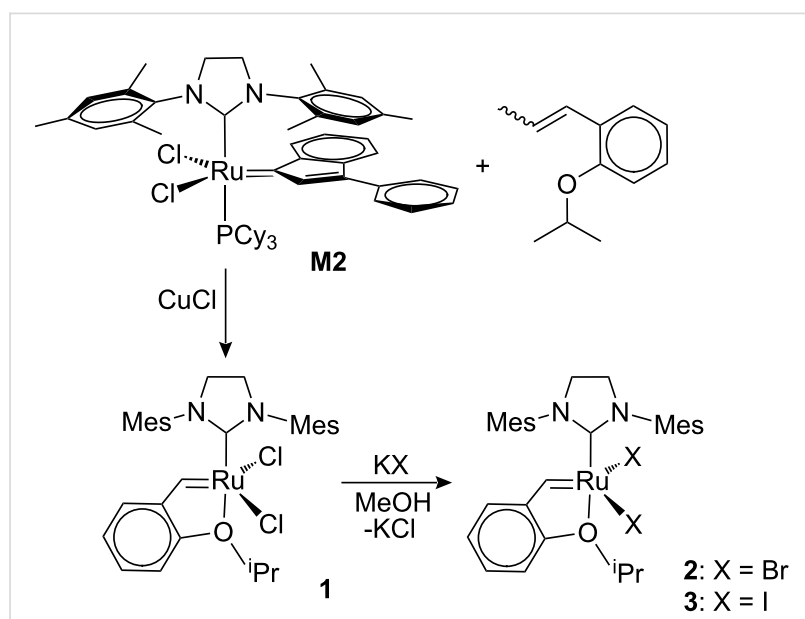

Scheme 1: Synthesis of 1, 2 and 3.

The halogen exchange reaction proved rapid at room temperature and reached an equilibrium comprising of three different species within less than $1 \mathrm{~h}$. The compounds were identified as the starting material $\mathbf{1}$, the desired product $\mathbf{2}$ (or $\mathbf{3}$ ), and a "mixed halogen" compound bearing a chloride and a bromide or an iodide ligand, respectively (Figure 2). Upon removal of the inorganic salts and addition of a further portion of $\mathrm{KBr}$ or $\mathrm{KI}$, the equilibrium can be directed towards the desired product. Typically, three successive additions of the potassium salt are necessary to obtain 2 or 3 in $90-92 \%$ yield and $95-98 \%$ purity. Efforts to further shift the equilibrium towards $\mathbf{2}$ or $\mathbf{3}$ have so far proved unsuccessful. The impurity, which could not be separated by recrystallisation or column chromatography, was identified as the "mixed halogen" compound and as revealed by field desorption mass spectrometry (FD-MS) measurements. FD-MS was found to be a suitable technique for the characteri- 


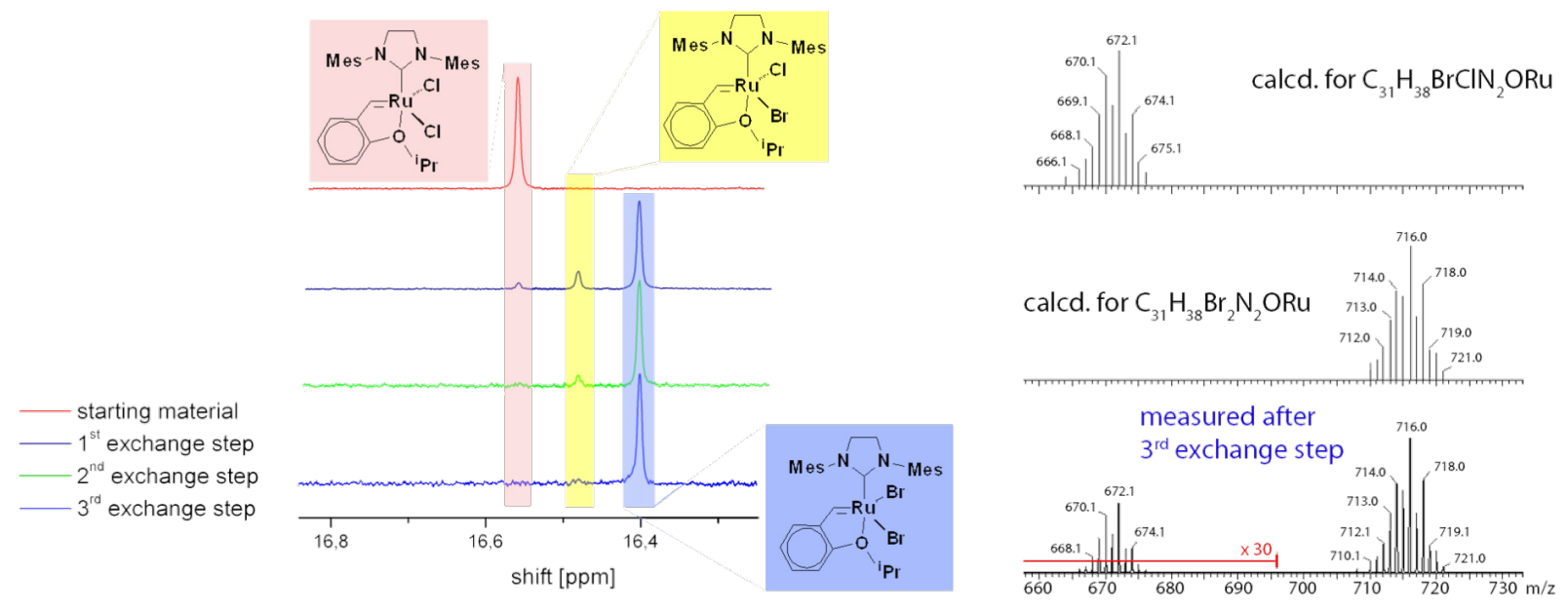

Figure 2: Details of the ${ }^{1} \mathrm{H}$ NMR spectra acquired during the synthesis of $\mathbf{2}$ and the FD-MS spectrum of $\mathbf{2}$ isolated after the $3^{\text {rd }}$ exchange step.

sation of this type of complex. Selecting appropriate acquisition parameters - the emitter current was slowly increased until desorption/ionisation started, in this way only molecular ions $\mathrm{M}^{+}$were observed (Figure 2).

Quantification was carried out by integration of the corresponding ${ }^{1} \mathrm{H}$ NMR signals. ${ }^{1} \mathrm{H}$ NMR spectra allowed convenient monitoring of the halide exchange by observing the carbene region at the very low field region of the spectra. The starting complex 1 exhibits a carbene peak at $16.56 \mathrm{ppm}$. Exchange of both chloride ligands for bromide shifts the carbene peak upfield to $16.40 \mathrm{ppm}$ and the mixed chloro-bromo complex appears at $16.48 \mathrm{ppm}$. In the case of $\mathbf{3}$, the carbene proton exhibits a singlet at $15.66 \mathrm{ppm}$ and the chloro-iodo species displays the corresponding peak at $16.10 \mathrm{ppm}$. All other features of the ${ }^{1} \mathrm{H}$ NMR spectrum of $\mathbf{2}$ are similar to those of $\mathbf{1}$ indicating slightly hindered rotation of the $\mathrm{N}$-heterocyclic carbene ligand and a trans-disposition of the two halide ligands. In contrast, the rotation of the NHC ligand around the $\mathrm{Ru}-\mathrm{NHC}$ bond in $\mathbf{3}$ is hindered as shown by a magnetic non-equivalency of the signals corresponding to the two mesityl moieties. The same behaviour was observed in the corresponding ${ }^{13} \mathrm{C} \mathrm{NMR}$ spectra (Supporting Information File 1).

\section{X-Ray}

Compound 3 crystallises in the monoclinic space group $P 2{ }_{1} / c$, and the overall geometrical arrangement is isostructural to the parent Hoveyda complex 1 (Figure 3). The ruthenium atom is pentacoordinated; the ligands form a slightly distorted square pyramid. The two iodides are, as expected, as supported by NMR data, trans-oriented in the basal plane of the square pyramid. The other positions in the basal plane are occupied by $\mathrm{C} 11$ (of the NHC ligand) and the atom $\mathrm{O} 1$. The strong ruthenium-carbon bond to the carbene was found in the apical position of the square pyramidal coordination around the metal center. Selected bond lengths and angles are provided in Table 1 . The overall geometry around the transition metal centre and most of the bond lengths in $\mathbf{3}$ are analogous to their related values in complex $\mathbf{1}$. This is surprising since the $\mathrm{Ru}-\mathrm{I}$ bond lengths are considerably longer compared to the $\mathrm{Ru}-\mathrm{Cl}$ bonds in $\mathbf{1}$. The bond angles vary slightly due to the significantly larger ionic radius of the iodide ligands [28], which lead to a slight distortion of the complex compared to the chloridebearing compound.

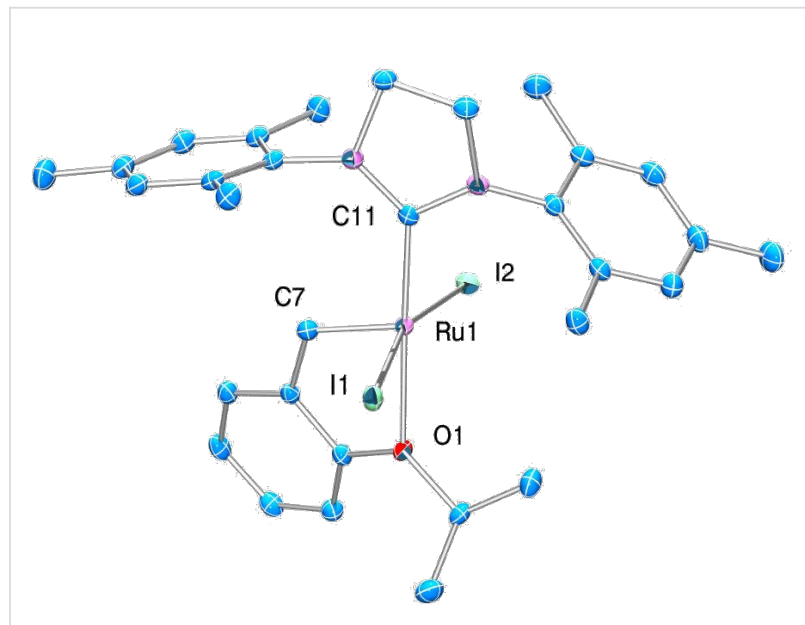

Figure 3: ORTEP drawing of 3. Thermal ellipsoids are drawn at $50 \%$ probability level. Hydrogen atoms are omitted for clarity. 
Table 1: Comparison of bond lengths and angles in $\mathbf{1}$ and $\mathbf{3}$.

\begin{tabular}{lll} 
Bond & Bond length in 3 [Å] & Bond length in 1 [A $]^{\mathrm{a}}$ \\
\hline Ru-C11 & 1.982 & 1.981 \\
Ru-C7 & 1.834 & 1.834 \\
Ru-O & 2.282 & 2.261 \\
Ru-X1 & 2.677 & 2.340 \\
Ru-X2 & 2.663 & 2.328 \\
& & \\
Angle & Bond angle in 3 [] & Bond angle in 1 [ $\left.{ }^{\circ}\right]^{a}$ \\
\hline C7-Ru-C11 & $102.94(7)$ & $101.5(14)$ \\
C7-Ru-O & $78.82(6)$ & $79.3(17)$ \\
C11-Ru-O & $178.13(5)$ & $176.2(14)$ \\
C7-Ru-X2 & $96.07(5)$ & $100.2(15)$ \\
C11-Ru-X2 & $96.08(4)$ & $96.6(12)$ \\
O-Ru-X2 & $84.35(3)$ & $86.9(9)$ \\
C7-Ru-X1 & $96.70(5)$ & $100.1(15)$ \\
C11-Ru-X1 & $90.78(4)$ & $90.9(12)$ \\
O-Ru-X1 & $88.35(3)$ & $85.3(9)$ \\
X2-Ru-X1 & $163.78(6)$ & $156.5(5)$ \\
\hline
\end{tabular}

Taken from Ref. [25]

Although the overall structure is quite similar to 1, some parameters concerning the ruthenium environment are worth discussing in more detail. As expected the main difference appears in the ruthenium halide bond lengths (in case of $\mathbf{3}$ about $0.3 \AA$ longer) and in the I-Ru-I angle (enlarged by some $7^{\circ}$ ). Both, the longer bond distance and the enlarged angle, are caused by the larger ionic radii of the iodides. The fact that the $\mathrm{Ru}-\mathrm{C}$ and $\mathrm{Ru}-\mathrm{O}$ distances are not significantly affected by the larger ionic radius of the halide ligands can be easily understood by considering the structural flexibility of the coordination polyhedron around the ruthenium atom. The $\mathrm{X} 1-\mathrm{Ru}-\mathrm{X} 2$ angle has a relatively high degree of freedom as the opposed position to the apical $\mathrm{Ru}-\mathrm{C}$ bond is not occupied, and thus the halide ions can avoid close contact with other ligands - which would distort the complex severely - by shifting their positions towards (chloride) or away from (iodide) the empty coordination position, depending on the $\mathrm{Ru}-\mathrm{X}$ distances.

\section{Catalytic testing of the compounds ROMP}

Initiators 1-3 were benchmarked in the ROMP of dimethyl bicyclo[2.2.1] hept-5-ene-2,3-dicarboxylate (4). The conversion of the monomer was monitored using arrayed ${ }^{1} \mathrm{H}$ NMR spectroscopy (Figure 4). Initiator 1 yields complete conversion of $\mathbf{4}$ at $20{ }^{\circ} \mathrm{C}$ in about $10 \mathrm{~min}$ (half-life $\mathrm{t}_{1 / 2} \approx 2 \mathrm{~min}$ ), while the dibromo derivative 2 requires about $35 \mathrm{~min}\left(\mathrm{t}_{1 / 2} \approx 7 \mathrm{~min}\right)$ for complete consumption of the monomer. Complex $\mathbf{3}$ is almost unable to initiate ROMP of $\mathbf{4}$ at room temperature.

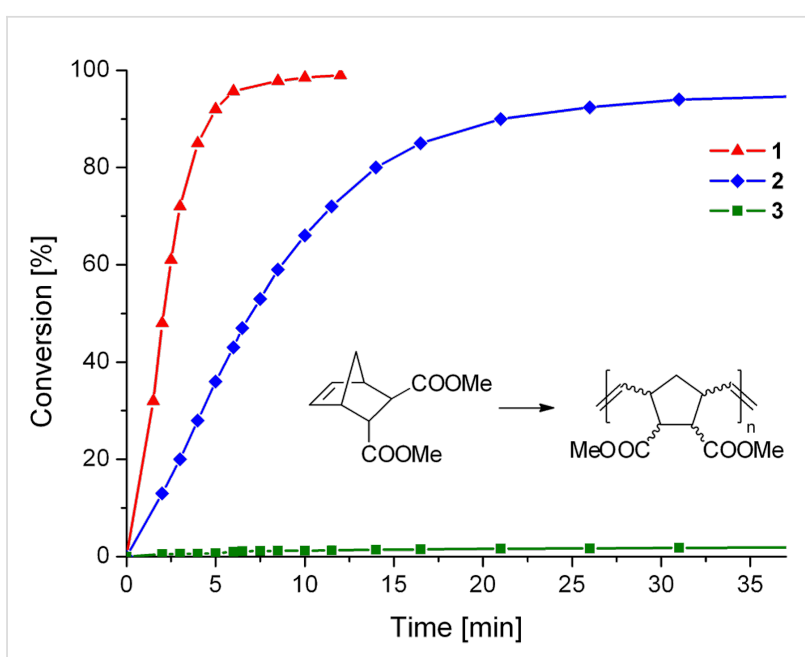

Figure 4: Polymerisation of 4 as a function of time, initiated by 1, 2 or 3, monitored by ${ }^{1} \mathrm{H}$ NMR spectroscopy; Reaction conditions: 4:initiator $=50: 1 ;[4]=0.1 \mathrm{~mol} / \mathrm{L}$; solvent: $\mathrm{CDCl}_{3} ; 20^{\circ} \mathrm{C}$.

Additional polymerisation tests were carried out using standard conditions [29], and, in addition to 4, two further monomers, namely 5,6-bis(methoxymethyl)bicyclo[2.2.1]hept-2-ene (5) and $(Z)$-cyclooct-5-ene-1,2-diyl diacetate (6), were used. Polymers made of $\mathbf{4}$ and $\mathbf{5}$ are not prone to backbiting, i.e., no secondary metathesis reaction affects the double bonds of the formed polymer. Therefore the average number molecular weight $\left(M_{\mathrm{n}}\right)$ can be used to establish an indirect, qualitative comparison of the ratio of initiation rate to propagation rate $\left(k_{\mathrm{i}}\right)$ $k_{\mathrm{p}}$ ) of a given initiator and monomer combination [30]. Polymers made with M2 and M31 were used for further comparison. M2 $\left(k_{\mathrm{i}} / k_{\mathrm{p}} \approx 1-0.01\right)$ is a typical initiator, producing in most cases polymers with high $M_{\mathrm{n}}$ values and high polydispersity indices (PDI) (Table 2, Entry 1 and 7), while polymers prepared with M31 $\left(k_{\mathrm{i}} / k_{\mathrm{p}} \approx 10-1000\right)$ are typically characterised by low $M_{\mathrm{n}}$ values and low PDIs [24] (Table 2, Entry 2 and 8).

Polymerisations initiated with the dichloro derivative 1 yield polymers with relatively low $M_{\mathrm{n}}$ and fairly narrow molecular weight distributions (Table 2, Entry 3 and 9), meaning that $k_{\mathrm{i}}$ is higher than $k_{\mathrm{p}}$ although both values are of the same order of magnitude. In the case of monomer $4, k_{\mathrm{i}} / k_{\mathrm{p}}$ increases upon changing from the chloro to the bromo ligands as can be deduced from the lower $M_{\mathrm{n}}$ value of the resulting polymer ( $68500 \mathrm{~g} / \mathrm{mol}$ in case of $\mathbf{2}$ and $106000 \mathrm{~g} / \mathrm{mol}$ in case of $\mathbf{1}$ as the initiator). As can be seen in Figure 4, the polymerisation with initiator $\mathbf{2}$ is distinctly slower than for the one initiated with $\mathbf{1}$, meaning that $k_{\mathrm{p}}$ for a polymerisation system consisting of $\mathbf{1}$ and $\mathbf{4}$ is distinctly higher than $k_{\mathrm{p}}$ for $\mathbf{2}$ and $\mathbf{4}$. Diiodo-bearing initiator $\mathbf{3}$ failed in the polymerisation of $\mathbf{4}$ at room temperature, but gave $75 \%$ conversion upon heating in toluene at $80{ }^{\circ} \mathrm{C}$ for $19 \mathrm{~h}$, meaning that $k_{\mathrm{p}}$ is very low in this system. In summary, 
Table 2: Polymerisation results ${ }^{\mathrm{a}}$
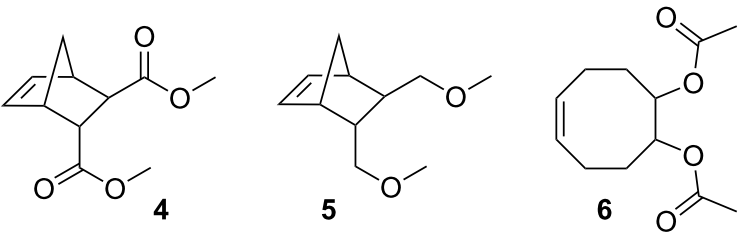

\begin{tabular}{|c|c|c|c|c|c|c|c|}
\hline Entry & Monomer & Initiator & Time [min] & Conversion [\%] & Yield [\%] & $M_{\mathrm{n}}^{\mathrm{b}}[\mathrm{kg} / \mathrm{mol}]$ & $\mathrm{PDI}^{\mathrm{b}}$ \\
\hline $1^{c}$ & 4 & M2 & 300 & 100 & 89 & 654 & 2.7 \\
\hline $2^{c}$ & 4 & M31 & 80 & 100 & 72 & 45.5 & 1.08 \\
\hline 3 & 4 & 1 & 80 & 100 & 85 & 106 & 1.2 \\
\hline 4 & 4 & 2 & 80 & 100 & 79 & 68.5 & 1.3 \\
\hline 5 & 4 & 3 & 1080 & 3 & - & - & - \\
\hline $6^{d}$ & 4 & 3 & 1140 & 75 & 47 & 53.1 & 2.3 \\
\hline $7^{c}$ & 5 & M2 & 360 & 100 & 87 & 967 & 2.3 \\
\hline $8^{c}$ & 5 & M31 & 90 & 100 & 74 & 64.7 & 1.09 \\
\hline 9 & 5 & 1 & 80 & 100 & 87 & 65.7 & 1.2 \\
\hline 10 & 5 & 2 & 80 & 100 & 77 & 75.3 & 1.5 \\
\hline 11 & 5 & 3 & 1080 & 78 & 44 & 82.8 & 8.8 \\
\hline $12^{\mathrm{d}}$ & 5 & 3 & 135 & 90 & 67 & 73.3 & 2.3 \\
\hline 13 & 6 & 1 & 75 & 95 & 54 & $130^{\mathrm{e}}$ & 5.2 \\
\hline 14 & 6 & 2 & 240 & 92 & 60 & $220^{e}$ & 1.9 \\
\hline 15 & 6 & 3 & 2880 & 58 & 37 & $190^{e}$ & 2.8 \\
\hline
\end{tabular}

aReaction conditions: Monomer:Initiator $=300: 1$; [monomer] $=0.2 \mathrm{~mol} / \mathrm{L}$; solvent: $\mathrm{CH}_{2} \mathrm{Cl}_{2} ; 20{ }^{\circ} \mathrm{C}$; ${ }^{b}$ determined by GPC, solvent THF, relative to polystyrene standards; ' ${ }^{c}$ values taken from Ref. [30]; ${ }^{d}$ solvent: toluene, temperature: $80{ }^{\circ} \mathrm{C}$; ${ }^{e}$ additionally a second peak with a $M_{\mathrm{n}}$ of about $1000 \mathrm{~g} / \mathrm{mol}$ was observed.

the following qualitative trends for the polymerisation of $\mathbf{4}$ with initiators 1, $\mathbf{2}$ and $\mathbf{3}$ could be established: the propagation rate constant decreases with increasing steric demand of the halo ligands (i.e., $\left.k_{\mathrm{p}}(\mathbf{1})>k_{\mathrm{p}}(2)>>k_{\mathrm{p}}(3)\right)$ and the ratio of initiation rate to propagation rate increases on going from 1 to 2 (i.e., $k_{\mathrm{i}} /$ $\left.k_{\mathrm{p}}(\mathbf{1})<k_{\mathrm{i}} / k_{\mathrm{p}}(2) \approx k_{\mathrm{i}} / k_{\mathrm{p}}(3)>1\right)$ but remains of the same order of magnitude.

By studying the polymerisation of monomer 5 with $\mathbf{1 , 2}$ and $\mathbf{3}$, a slightly different picture emerged. While the trend for $k_{\mathrm{p}}$ is the same as in the case of monomer $\mathbf{4}, k_{\mathrm{i}} / k_{\mathrm{p}}$ decreases with increasing steric bulk of the halo ligands i.e., $k_{\mathrm{i}} / k_{\mathrm{p}}(\mathbf{1})>k_{\mathrm{i}} / k_{\mathrm{p}}(\mathbf{2})$ $>k_{\mathrm{i}} / k_{\mathrm{p}}(\mathbf{3})$, meaning that the decrease of $\mathrm{k}_{\mathrm{i}}$ within the series is more pronounced than the decrease of $k_{\mathrm{p}}$.

At this stage a comment on the presence of the small amounts of mixed halogen complexes $(\mathrm{Br}-\mathrm{Cl}-\mathrm{Ru}$ and $\mathrm{Cl}-\mathrm{I}-\mathrm{Ru}$ both $<$ $5 \%)$ is necessary. These species might be responsible for the somewhat higher PDIs of the polymers prepared with 2 compared to those prepared with $\mathbf{1}$. Still it can be ruled out that the mixed halogen species is the only active initiator (otherwise the low $M_{\mathrm{n}}$ values observed for the polymers would not be explicable). Accordingly, the activity of the corresponding mixed halogen species is similar to the activity of $\mathbf{2}$ or $\mathbf{3}$, respectively.

In contrast to monomers $\mathbf{4}$ and $\mathbf{5}$, monomer $\mathbf{6}$ gives polymers which can be degraded by secondary metathesis reactions [31]. Complex 1 polymerises 300 equiv of 6 in $75 \mathrm{~min}$ at room temperature with a conversion of $95 \%$ ( $54 \%$ isolated yield). The $M_{\mathrm{n}}$ of this polymer was $130600 \mathrm{~g} / \mathrm{mol}$. Initiator 2 requires $4 \mathrm{~h}$ to achieve a conversion higher than $90 \%$ (60\% yield) and the corresponding $M_{\mathrm{n}}$ is $220000 \mathrm{~g} / \mathrm{mol}$. Finally, 3 gave only $58 \%$ conversion after a reaction time of $48 \mathrm{~h}\left(M_{\mathrm{n}}=190000 \mathrm{~g} / \mathrm{mol}\right)$. From these data, it is evident that $k_{\mathrm{p}}$ decreases within the series $\mathbf{1}, \mathbf{2}$ and $\mathbf{3}$, and that $k_{\mathrm{i}} / k_{\mathrm{p}}$ in the case of $\mathbf{6}$ is considerably smaller when compared to the monomers discussed above.

In all cases, poly6 degraded over time (Figure 5), i.e., the overall $M_{\mathrm{n}}$ decreases after a certain point and broad multimodal molecular weight distributions are observed. In the case of $\mathbf{1}$ and $\mathbf{2}$, the rate of degradation is relatively low when compared to the rate of polymerisation, allowing for the preparation of high molecular weight poly6 combined with high conversion in short reaction times. In contrast, in the case of $\mathbf{3}$, degradation is an important issue and poly6 of high molecular weight, formed 


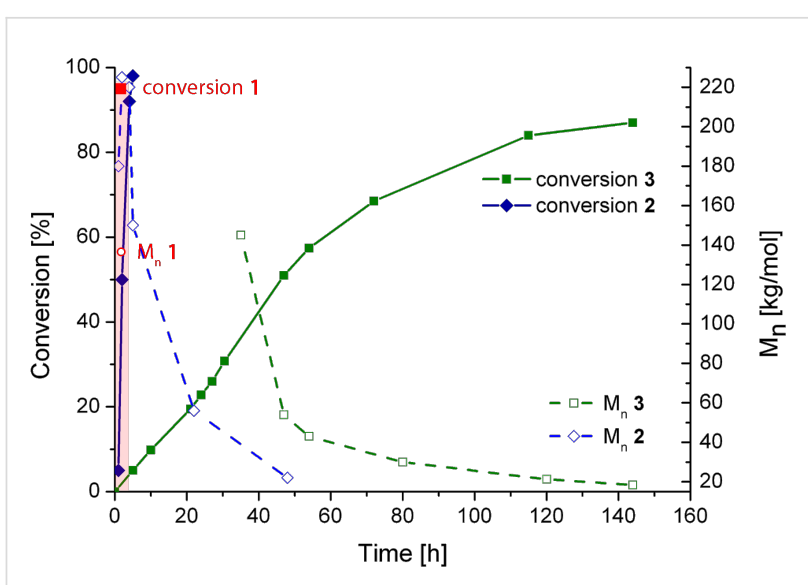

Figure 5: Polymerisations of 6 as a function of time, initiated by 1-3, monitored by ${ }^{1} \mathrm{H}$ NMR spectroscopy (solid lines) and GPC (dashed lines); reaction conditions: 6 : initiator $=300: 1 ;[6]=0.2 \mathrm{~mol} / \mathrm{L}$; solvent: $\mathrm{CH}_{2} \mathrm{Cl}_{2} ; 20^{\circ} \mathrm{C}$. The red circle symbolises the number molecular weight of poly 6 initiated by 1 (the red square symbolises the conversion after $1 \mathrm{~h}$ reaction time); reaction conditions for the polymerisation with 3 is $6: 3=100: 1 ;[1]=0.05 \mathrm{~mol} / \mathrm{L} ;$ solvent: $\mathrm{CH}_{2} \mathrm{Cl}_{2} ; 20^{\circ} \mathrm{C}$ ).

at the early stages of the polymerisation, is substantially degraded long before the remaining monomer is completely consumed.

\section{RCM, enyne cycloisomerisation and cross metathesis}

Catalytic activities of $\mathbf{1}, \mathbf{2}$ and $\mathbf{3}$ were then evaluated in RCM of diethyl diallylmalonate (7). The reaction progress is shown in Figure 6 (for details see Table 3). While 1 and 2 perform equally, $\mathbf{3}$ is the slowest catalyst for this transformation. Nevertheless, the performance of $\mathbf{3}$ is, when taking the results from the benchmarking in ROMP into account, remarkable. Complex $\mathbf{3}$ is a fairly good catalyst for this easy transformation and outperforms M2 [32].

With these results at our disposal, we concentrated on further elucidating the catalytic potential of $\mathbf{3}$ in RCM, enyne cycloisomerisation and cross metathesis (CM).

Benchmark substrates were selected according to protocols for testing of metathesis catalysts [33]. Substrates with low steric hindrance (Table 3, Entry 1 and 3) were transformed with satisfying results. Even the formation of tetra-substituted olefin bonds (Table 3, Entry 2 and 4) was feasible, although yields fell short in comparison to those obtained with catalyst $\mathbf{1}$. In cross metathesis, $\mathbf{3}$ was not particularly active in coupling terminal mono-substituted olefins with methyl acrylate and failed in the CM of di-substituted terminal olefins (Table 3, Entry 5 and 6) under the reaction conditions used. An interesting example is the cross metathesis of erucic acid with tert-butyl acrylate (Table 3, Entry 7). In this case, very similar results were

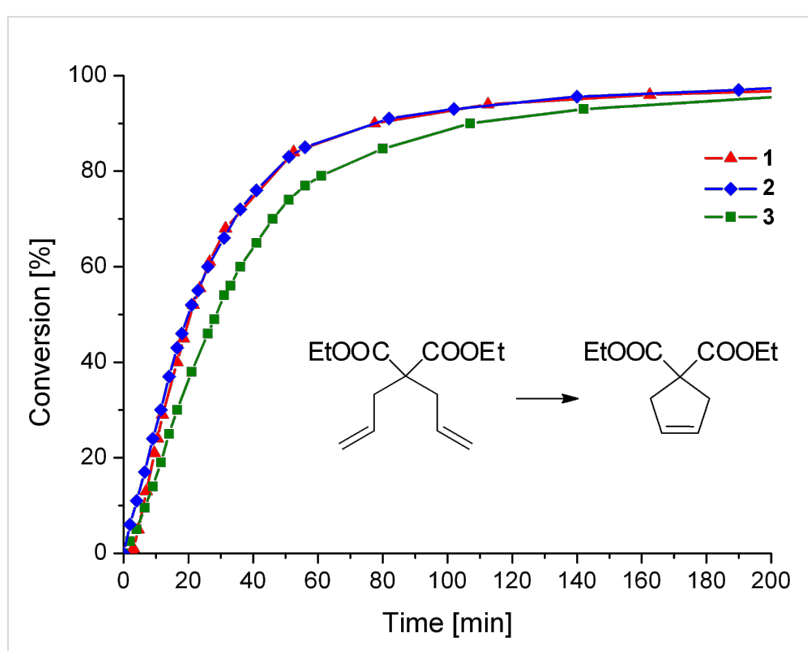

Figure 6: The RCM reaction of 7 as a function of time, catalysed by 1 , $\mathbf{2}$ or $\mathbf{3}$, monitored by ${ }^{1} \mathrm{H}$ NMR spectroscopy; Reaction conditions: 7: catalyst $=100: 1 ;[7]=0.1 \mathrm{~mol} / \mathrm{L}$; solvent: $\mathrm{CDCl}_{3} ; 20^{\circ} \mathrm{C}$.

obtained with $\mathbf{1}$ and 3. Still a difference exists as only $\mathbf{1}$ produced small amounts of the homodimer of the acrylate. Finally, the homo-dimerisation of an acrylate was our last test reaction. Diiodo-complex 3 catalyses the dimerisation of 2-hydroxyethyl acrylate, but compared to $\mathbf{1}$, catalyst $\mathbf{3}$ is considerably slower (Table 3, Entry 8).

\section{Conclusion}

The results presented indicate a slight activity change in various olefin metathesis reactions when changing the anionic co-ligands from chlorides to iodides. In general, the catalysts are good for RCM and enyne metathesis of moderately hindered substrates; however, they exhibit low activity towards catalyzing transformations of sterically hindered substances. The parent dichloro derivative $\mathbf{1}$ is the most active catalyst in every transformation studied. The diiodo derivative $\mathbf{3}$ is a slightly inferior catalyst in RCM, enyne metathesis and CM, but 3 is reluctant or even ineffective to initiate ROMP of norbornene derivatives. Another example of selectivity was observed during the cross metathesis of an internal olefin with an electron deficient alkene, where in the case of $\mathbf{3}$ no side reaction (i.e., homodimerisation of the electron-deficient olefin) occurred. Thus 3 might prove in the future an interesting catalyst for special applications demanding selectivity.

The current results might be of particular importance whenever the transformation of charged substrates is of interest. In light of the easy exchange of anionic co-ligands in ruthenium-based olefin metathesis catalysts, anionic counterions should preferably be chlorides or bromides but not iodides. The latter might cause a decrease of the reaction rate or might even impede the desired transformation. 


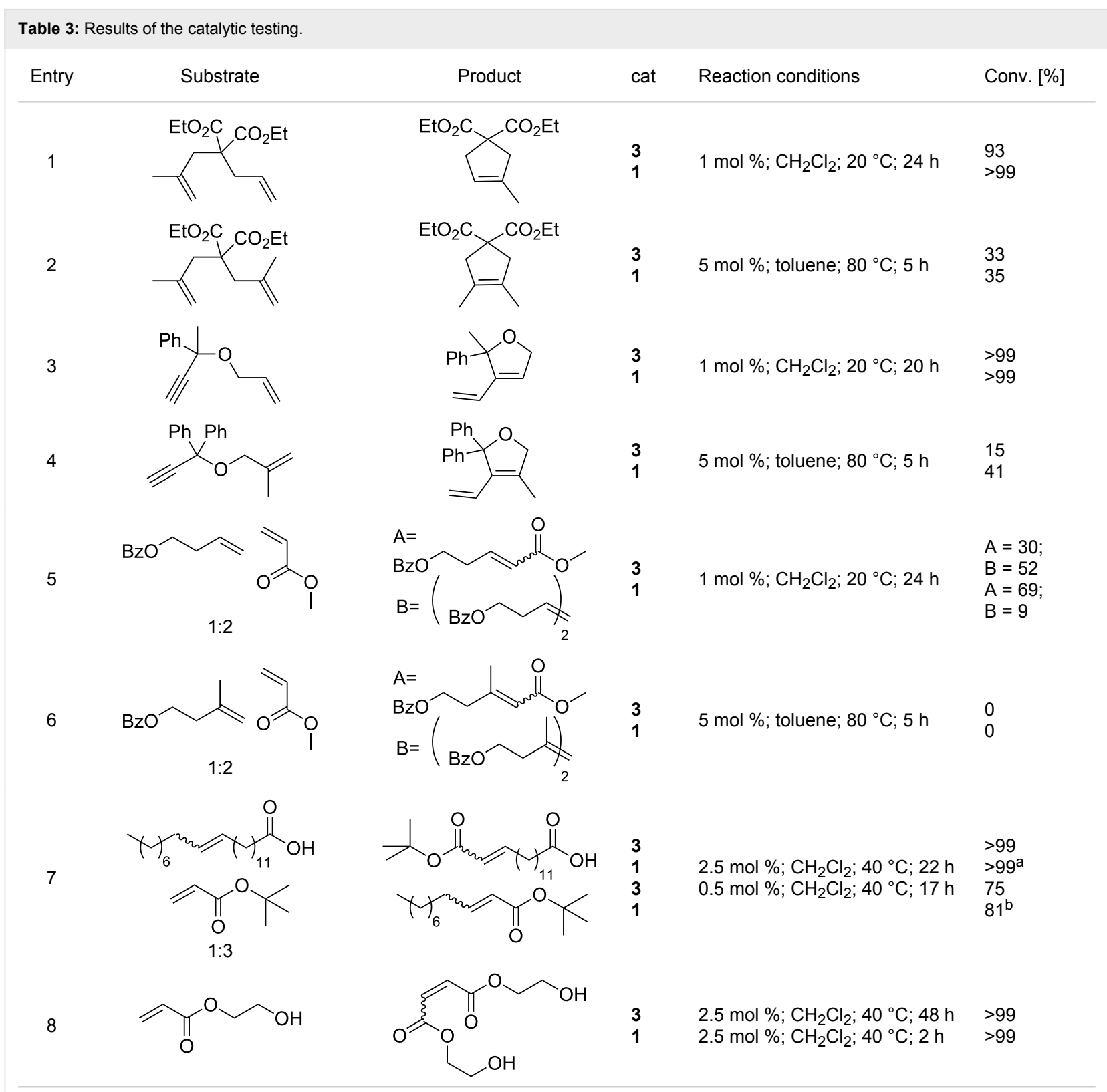

${ }^{a} 4 \%$ homodimer of acrylate; ${ }^{b} 1 \%$ homodimer of acrylate.

\section{Supporting Information}

Supporting information contains full experimental and spectral data for complexes 1-3 and the test reactions.

\section{Supporting Information File 1}

[http://www.beilstein-journals.org/bjoc/content/ supplementary/1860-5397-6-125-S1.pdf]

\section{Acknowledgements}

Financial support by the European Community (CP-FP 2114682 EUMET) is gratefully acknowledged. The Higher Education Commission of Pakistan is gratefully thanked for financial support of M. A. as is Umicore AG for the generous gift of materials. SPN is a Royal Society-Wolfson Research Merit holder.

\section{References}

1. Weskamp, T.; Schattenmann, W. C.; Spiegler, M.; Herrmann, W. A. Angew. Chem., Int. Ed. 1998, 37, 2490-2493.

doi:10.1002/(SICI)1521-3773(19981002)37:18<2490::AID-ANIE2490>3 . $0 . \mathrm{CO} ; 2-\mathrm{X}$ 
2. Huang, J.; Stevens, E. D.; Petersen, J. L.; Nolan, S. P. J. Am. Chem. Soc. 1999, 121, 2674-2678. doi:10.1021/ja9831352

3. Scholl, M.; Ding, S.; Lee, C. W.; Grubbs, R. H. Org. Lett. 1999, 1, 953-956. doi:10.1021/ol990909q

4. Grubbs, E. H., Ed. Handbook of Metathesis; Wiley-VCH: Weinheim, 2003.

5. Vougioukalakis, G. C.; Grubbs, R. H. Chem. Rev. 2010, 110, 1746-1787. doi:10.1021/cr9002424

6. Szadkowska, A.; Grela, K. Curr. Org. Chem. 2008, 12, 1631-1647. doi:10.2174/138527208786786264

7. Szadkowska, A.; Gstrein, X.; Burtscher, D.; Jarzembska, K.; Wozniak, K.; Slugovc, C.; Grela, K. Organometallics 2010, 29, 117-124. doi:10.1021/om900857w

8. Samojłowicz, C.; Bieniek, M.; Grela, K. Chem. Rev. 2009, 109, 3708-3742. doi:10.1021/cr800524f

9. Díez-González, S.; Marion, N.; Nolan, S. P. Chem. Rev. 2009, 109, 3612-3676. doi:10.1021/cr900074m For the use of NHCs in late transition metal catalysis.

10. Krause, J. O.; Nuyken, O.; Wurst, K.; Buchmeiser, M. R. Chem.-Eur. J. 2004, 10, 777-784. doi:10.1002/chem.200305031

11. Halbach, T. S.; Mix, S.; Fisher, D.; Maechling, S.; Krause, J. O.; Sievers, C.; Blechert, S.; Nuyken, O.; Buchmeiser, M. R. J. Org. Chem. 2005, 70, 4687-4694. doi:10.1021/jo0477594

12. Conrad, J. C.; Amoroso, D.; Czechura, P.; Yap, G. P. A.; Fogg, D. E. Organometallics 2003, 22, 3634-3636. doi:10.1021/om030494j

13. Monfette, S.; Camm, K. D.; Gorelsky, S. I.; Fogg, D. E. Organometallics 2009, 28, 944-946. doi:10.1021/om900006f

14. Buchmeiser, M. R.; Kumar, S.; Ahmad, I. Abstracts of Papers. 240th ACS National Meeting, Boston, MA, United States, Aug 22-26, 2010; INOR-61.

15. Sanford, M. S.; Love, J. A.; Grubbs, R. H. J. Am. Chem. Soc. 2001 123, 6543-6554. doi:10.1021/ja010624k

16. Seiders, T. J.; Ward, D. W.; Grubbs, R. H. Org. Lett. 2001, 3, 3225-3228. doi:10.1021/ol0165692

17. Gillingham, D. G.; Kataoka, O.; Garber, S. B.; Hoveyda, A. H. J. Am. Chem. Soc. 2004, 126, 12288-12290. doi:10.1021/ja0458672

18. van Veldhuizen, J. J.; Campbell, J. E.; Giudici, R. E.; Hoveyda, A. H. J. Am. Chem. Soc. 2005, 127, 6877-6882. doi:10.1021/ja050179j

19. Funk, T. W.; Berlin, J. M.; Grubbs, R. H. J. Am. Chem. Soc. 2006, 128, 1840-1846. doi:10.1021/ja055994d

20. Tanaka, K.; Böhm, V. P. W.; Chadwick, D.; Roeper, M.; Braddock, D. C. Organometallics 2006, 25, 5696-5698. doi:10.1021/om060913n

21. Leitgeb, A.; Wappel, J.; Slugovc, C. Polymer 2010, 51, 2927-2946. doi:10.1016/j.polymer.2010.05.002

22. Jafarpour, L.; Schanz, H. J.; Stevens, E. D.; Nolan, S. P. Organometallics 1999, 18, 5416-5419. doi:10.1021/om990587u

23. Fürstner, A.; Grabowski, J.; Lehmann, C. W. J. Org. Chem. 1999, 64, 8275-8280. doi:10.1021/jo991021i

24. Burtscher, D.; Lexer, C.; Mereiter, K.; Winde, R.; Karch, R.; Slugovc, C. J. Polym. Sci., Part A: Polym. Chem. 2008, 46, 4630-4635. doi:10.1002/pola.22763

25. Garber, S. B.; Kingsbury, J. S.; Gray, B. L.; Hoveyda, A. H. J. Am. Chem. Soc. 2000, 122, 8168-8179. doi:10.1021/ja001179g

26. Sanford, M. S.; Love, J. A.; Grubbs, R. H. Organometallics 2001, 20 , 5314-5318. doi:10.1021/om010599r

27. Gatard, S.; Kahlal, S.; Méry, D.; Nlate, S.; Cloutet, E.; Saillard, J.-Y.; Astruc, D. Organometallics 2004, 23, 1313-1324. doi:10.1021/om030608r
28. The ionic radii of chloride and iodide are $167 \mathrm{pm}$ and $206 \mathrm{pm}$; the covalent radii of chlorine and iodine are $99 \mathrm{pm}$ and $133 \mathrm{pm}$.

29. Demel, S.; Schoefberger, W.; Slugovc, C.; Stelzer, F. J. Mol. Catal. A: Chem. 2003, 200, 11-19. doi:10.1016/S1381-1169(03)00048-7

30. Broggi, J.; Urbina-Blanco, C. A.; Clavier, H.; Leitgeb, A.; Slugovc, C.; Slawin, A. M. Z.; Nolan, S. P. Chem.-Eur. J. 2010, 16, 9215-9225. doi:10.1002/chem.201000659

31. Alb, A. M.; Enohnyaket, P.; Craymer, J. F.; Eren, T.; Coughlin, E. B.; Reed, W. F. Macromolecules 2007, 40, 444-451. doi:10.1021/ma062241i

32. Bieniek, M.; Michrowska, A.; Usanov, D. L.; Grela, K. Chem.-Eur. J. 2008, 14, 806-818. doi:10.1002/chem.200701340

33. Ritter, T.; Hejl, A.; Wenzel, A. G.; Funk, T. W.; Grubbs, R. H. Organometallics 2006, 25, 5740-5745. doi:10.1021/om060520o

\section{License and Terms}

This is an Open Access article under the terms of the Creative Commons Attribution License

(http://creativecommons.org/licenses/by/2.0), which permits unrestricted use, distribution, and reproduction in any medium, provided the original work is properly cited.

The license is subject to the Beilstein Journal of Organic Chemistry terms and conditions: (http://www.beilstein-journals.org/bjoc)

The definitive version of this article is the electronic one which can be found at: doi:10.3762/bjoc. 6.125 